\title{
Phylogenetic diversity of procaryotae and their contribution to excess sludge demineralization in a gravel contact oxidation reactor
}

\author{
S. $\operatorname{Lin}^{1}$, Y. Jin ${ }^{1}$, L. Fu ${ }^{1} \&$ C. Quan ${ }^{2}$ \\ ${ }^{1}$ School of City and Environmental Science, \\ Northeast Normal University, Changchun, People's Republic of China \\ ${ }^{2}$ Jilin University, Changchun, People's Republic of China
}

\begin{abstract}
Phylogenetic diversity of procaryotae and their function to excess sludge demineralization in a gravel contact oxidation reactor (GCOR) were studied by constructing a 16SrRNA library and PCR-based molecular surveys of environmental 16SrRNA genes. The sequence analysis of 16SrRNA genes indicated that granular bacterial communities were composed of Proteobacteria, Bacteroidetes, Nitrobacteraceae, Low $\mathrm{G}+\mathrm{C}$ and the Unclassified bacteria group. The dominant members were $\beta-, \gamma$-Proteobacteria. Different kinds of bacteria which contributed to excess sludge decrement were associated with uncoupled metabolism, diverse bacterial interactive behaviour and domination of slow growers.

Keywords: suspended granular in gravel contact oxidation reactor (GCOR), phylogenetic diversity of microorganisms, 16SrDNA library, excess sludge reduction.
\end{abstract}

\section{Introduction}

Biological wastewater treatment involves the transformation of dissolved and suspended organic contaminants to biomass and evolved gases $\left(\mathrm{CO}_{2}, \mathrm{CH}_{4}, \mathrm{~N}_{2}\right.$, and $\mathrm{SO}_{2}$ ) which are separated from the treated water [1]. Excess biomass produced within processes is creating environmental challenges due to expensive ultimate disposal options such as landfill and/or incineration [2] and disposal costs may account for $60 \%$ of total plant operating costs (Horan [20]). So it is 
necessary to develop an innovative technology for reducing the amount of biomass produced.

Excess sludges contain inert solid and biological solid, collectively called biomass, the latter being derived through metabolism of pollutants. Biomass contains a diverse and interactive microbial population consisting of cells. These heterogeneous microbial cells are undergoing life cycles and reproducing with relationships between the different types of cells being characterised by symbiotic, cooperative, aggressive and competitive behaviour. As a result of these relationships, aerobic, anaerobic and anoxic environments will determine the availability of reducing equivalents thus influencing the metabolic efficiency [1]. There is one possible solution to create a feasible engineering approach to this problem: developing one reactor or equipment provides aerobic, anaerobic and anoxic environments, which reduces the excess biomass production effectively by diversity of aerobic, anaerobic and facultative procaryotae.

Research indicated that gravel contact oxidation reactor (GCOR) reached this engineering approach. In GCOR ecosystem, procaryotae community structure and population play an essential role in the biodegradation of organic pollutants derived from sewage and demineralization of excess biomass produced in treatment process. In contrast to our knowledge of activated sludge microbiology, the phylogenetic diversity of granules and biofilms in GCOR is poorly understood.

Traditional microbial cultivation techniques have limited their investigation to data because of long generation time of some bacteria and poor counting efficiencies [3]. The difficulties inherent in these techniques have restricted spatial investigation of phylogenetic diversity in GCOR. The development of vital staining and new molecular biology techniques allowed studies to focus on the characterization and assessment of microbial metabolic potential in situ, without prior cultivation, to predict the responses of ecosystems to reactor environmental perturbations.

The objective of the study are to analyze (I) the phylogenetic diversity of procaryotae in GCOR; (II) the main functional groups of procaryotae in GCOR, using homology analysis of 16SrDNA sequence and (III) the contribution of diverse procaryotae to excess biomass reduction in GCOR.

\section{Materials and methods}

\subsection{Operation of a GCOR}

Gravel contact oxidation reactor (GCOR) is a coniform reactor, which diameter was $40 \mathrm{~cm}$ and height was $100 \mathrm{~cm}$, respectively. Crushed stone globular aggregates in diameters $10 \mathrm{~cm}$ were filled as carrier, and aerator was located the bottom of reactor by continuous aeration (Fig. 1) in order to make an aerobic ecological niche on the surface of crushed stone globular aggregate and anaerobic ecological niche in its pore. Source water for experiment was taken from dumb well located in the campus of Northeast Normal University, Changchun, China. Seeded sludge was taken from a local sewage treatment 
plant, Changchun, China. The HRT was controlled at $12 \mathrm{~h}$ and the sludge cultivation and subsequent operation were all conducted in a temperature controlled room at $20^{\circ} \mathrm{C}$. After one month cultivation, source water was continuously fed to GCOR for 5 months. The effluents quality of treated sewage reached the discharge standard to river of China and no excess sludge discharged specially. The source water and treated water quality are shown in Table 1.

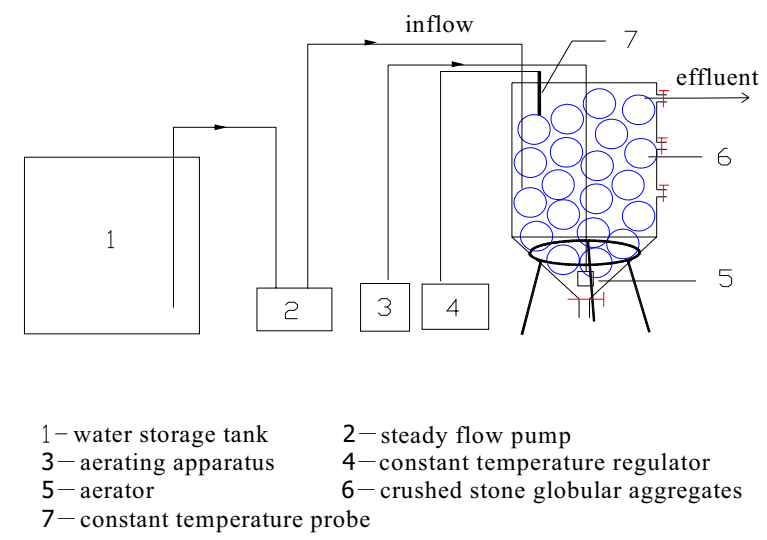

Figure 1: GCOR experiment system.

Table 1: $\quad$ The source water and treated water quality.

\begin{tabular}{|c|c|c|c|c|c|c|}
\hline $\begin{array}{l}\text { Water } \\
\text { sample }\end{array}$ & $\mathrm{PH}$ & $\begin{array}{l}\mathrm{COD}_{\mathrm{cr}} \\
\left(\mathrm{mg} \mathrm{L}^{-1}\right)\end{array}$ & $\begin{array}{l}\mathrm{SS} \\
\left(\mathrm{mg} \mathrm{L}^{-1}\right)\end{array}$ & $\begin{array}{l}\mathrm{BOD}_{5} \\
\left(\mathrm{mg} \mathrm{L}^{-1}\right)\end{array}$ & $\begin{array}{l}\mathrm{NH}_{3}-\mathrm{N} \\
\left(\mathrm{mg} \mathrm{L}^{-1}\right)\end{array}$ & $\begin{array}{l}\text { Animal/ } \\
\text { vegetable oil } \\
\left(\mathrm{mg} \mathrm{L}^{-1}\right)\end{array}$ \\
\hline $\begin{array}{l}\text { Source } \\
\text { water }\end{array}$ & 8.43 & 336.87 & 298.37 & 160.5 & 58.61 & 2.35 \\
\hline $\begin{array}{l}\text { Treated } \\
\text { water }\end{array}$ & 7.39 & 32 & 28.87 & 10.17 & 15.59 & 0.28 \\
\hline
\end{tabular}

\subsection{Sample processing}

Biofilm sample was collected from the surface of crushed stone globular aggregates, and sludge sample was collected from pore of crushed stone globular aggregates, respectively. The sample was introduced into a sterile plastic tubes $(200 \mathrm{ml})$. After centrifugation and precipitation, the sedimentation was located in $-20^{\circ} \mathrm{C}$ for DNA extraction.

\subsection{DNA extraction and PCR amplification}

DNA was extracted following method "freeze-thaw and lysozyme-SDS lysis" described in 1999 by Bourrain et al. [19], with slight modification. In order to improve DNA extraction from activated sludge, pre-lysis washing was used before DNA extraction. The sedimentation of $1 \mathrm{~g}$ and $5 \mathrm{ml} 0.1 \mathrm{M}$ sodium 
phosphate buffer were mixed and gently shaken for $1 \mathrm{~h}$ in an Orbital Mixer incubator at room temperature, centrifuged at $16000 \mathrm{~g}$ for $10 \mathrm{~min}$, and the sedimentation were collected for DNA extraction [3]. 16SrDNA fragments were amplified using EUB530F (5'-GTGCCAGCA/GGCCGCGG-3') and EUB1490R (5'-GGTTACCTTGTTACGACTT-3') primers, which are specific for universally conserved bacterial 16SrDNA sequences. These sequences were targeted to $E$. coli 16SrDNA positions 514-529 and 1491-1509. PCR amplification reactions were carried out using TAKARA Teq Kit reagents in $50 \mu \mathrm{l}$ of PCR mixture with $15 \mathrm{mM} \mathrm{MgCl}_{2}$ and $1 \mu \mathrm{L}$ of each primer. Hot start PCR was performed at $95^{\circ} \mathrm{C}$ for $5 \mathrm{~min}$ and 30 cycles were performed as followed: the denaturation at $94^{\circ} \mathrm{C}$ for $1 \mathrm{~min}$, the annealing at $50^{\circ} \mathrm{C}$ for $1 \mathrm{~min}$ and primer extension at $72^{\circ} \mathrm{C}$ for $1.5 \mathrm{~min}$. Finally, an extension step was carried out at $72^{\circ} \mathrm{C}$ for $10 \mathrm{~min}$. PCR products size and yield were estimated by comparing with standards on $1 \%$ agarose gels. The gels were stained in EB $(0.5 \mathrm{mg} / \mathrm{L})$ and visualized under UV light. Band with $1 \mathrm{~kb}$ was cut and purified by PCR products purified kit. Each amplicon from the produced mixture of 16SrDNA was ligated into a plasmid, each of which was transformed into one competent $E$. coli cells by TA cloning kit (TaKaRa Biotechnology (Dalian) Co., Ltd.). The plasmids inserts from $E$. coli cells were extracted by alkaline cracking method and the amplicons were digested with Res, which recognise and cut DNA at specific nucleotide motifs.

\subsection{SrDNA sequence analysis}

Electropositive molecule inserted 16SrDNA fragments were sequenced by Sangon Bio-tech. Co., Shanghai. Partial 16SrDNA sequences were analyzed with the program CHIMERA_CHECK version 2.7 and those 16SrDNA clones with the same sequence were defined into one operational taxonomic unit (OTU). Group level classification and closest relative confirmed of each clone were then made using the BLAST search engine from the GenBank nucleotide sequence database. Phylogenetic trees were constructed using DNAMAN 5.29 software package. The stability of phylogenetic trees was tested by bootstrap analysis using PHYLIP software package. Bootstrap analysis was performed with 100 replicates and values $\geqslant 50 \%$ are shown above the corresponding nodes.

\subsection{Contribution of diverse procaryotae to excess biomass reduction in GCOR}

The procaryotae both from biofilm and inner sludge were divided into aerobic, anaerobic, facultative anaerobic and growth slowness bacteria, according to their metabolic type and rate. Several 16SrDNA clone libraries were constructed from granule samples to identify the main functional bacterial communities, so as to analysis their contribution to sewage degradation and excess sludge least emission. 


\subsection{Nucleotide sequence nomenclature}

Bacteria domain clones from biofilm and inner sludge of the crushed stone globular aggregates are prefixed BF and IS, respectively. The accession numbers of sequences in present study have been deposited in GenBank and DDJB database. The sequence data have been submitted to Genbank database under Accession numbers: DQ839320-DQ839351.

\section{Results}

\subsection{SrDNA clone library construction}

Clone libraries were created from partial 16SrRNA genes amplified from DNA both of biofilm and inner sludge derived from crushed stone globular aggregates, which located in GCOR. The chimeras of sequences were excluded by screening using CHIMERA_CHECK. The final numbers of 16SrRNA genes clones retained for phylogenetic analysis are 80, in which 46 clones (19 OTUs) isolated from biofilm and 34 clones (21 OTUs) isolated from inner sludge, respectively.

\subsection{SrDNA sequences phylogenetic analysis}

The most abundant sequences were those related to $\beta$-Proteobacteria group ( $20 \%$ clones from biofilm and 26\% from inner sludge, respectively). Next were those related to $\gamma$-Proteobacteria (20\% clones from both of biofilm and inner sludge) and Bacteroides groups (about 13\% clones only from biofilm). Clones related to $\delta$-Proteobacteria were also found in libraries from biofilm and inner sludge, whereas sequences related to Nitrobacteraceae (Nitrospia sp.) were found only from biofilm and low G+C Gram-positive bacteria (Acidobacteria) was found only from inner sludge. In addition to the clones mentioned above, 3 clones from biofilm closely related Uncultured bacterium, which could not be classified into any bacteria group, but only were gave definition bacteria and isolated from environmental sample in GenBank.

Phylogenetic analysis showed that the majority of clones related to $\beta$-roteobacteria and Bacteroides groups were not closely related to known species or genera and that the phylogentic distribution of the clones was similar in the libraries from biofilm and inner sludge. Within $\beta$-Proteobacteria (Fig. 7) the partial sequences of clones BF-5 and BF-6 were similar to Acidovorax sp. BSB421 and Leptothrix sp. S1.1 isolated from activated sludge [15], respectively. The partial sequences of clones BF-23 and BF-17 in Bacteroides groups were very similar to Gemmatimonas aurantiace genue and uncultured Gemmatimonas bacterium, both belonged to Gemmatimonadales (Fig. 5). Furthermore, in $\gamma$-Proteobacteria IS-25 was very close to Glaucimonas multicolorus and Dokdonella koreensis strain DS-140, two novel Xanthomonadales species isolated from potting soil [17]; BF-3 was similar to Xanthomonadaceae bacterium and BF-25 was a little related to a cluster with Klebsiella planticola, Enterobacter cloacae isolate CR1 and Erwinia alni DSM 
11811 (Fig. 6). One partial sequence of clone BF-4 in $\alpha$-proteobacteria subdivision was very close to Alpha proteobacterium, which was closely related to Roseomonas gilardii strain ATCC 49956 16S rRNA gene (Fig. 2). Among the clones in unclassified group, only BF-9 was very similar to Nitrospira sp., others were a little related to uncultured bacterium only isolated from environment sample and without any classification (Fig. 4).

In contrast to the aforementioned groups, the clones belonging to $\delta$-proteobacteria subdivision were not closely related to any known species (Fig. 3).

\subsection{5}
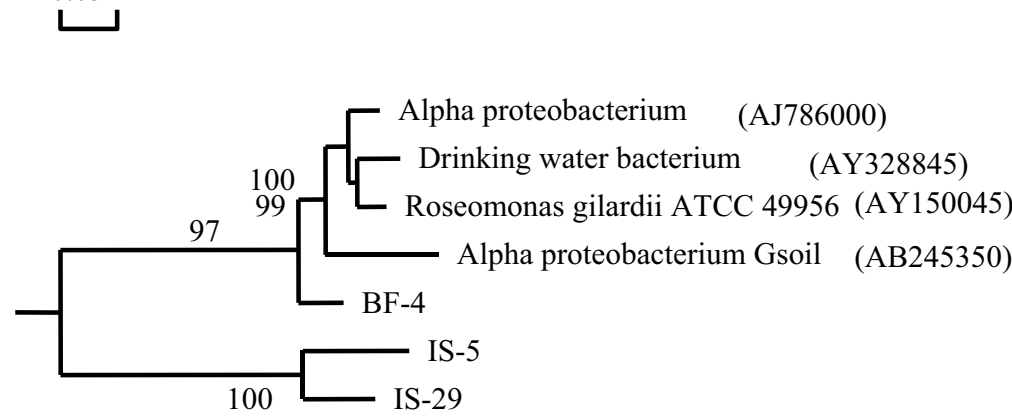

Figure 2: Phylogenetic analysis of bacterial clones related to $\alpha$-Proteobacteria.<smiles>[19OH2]</smiles>

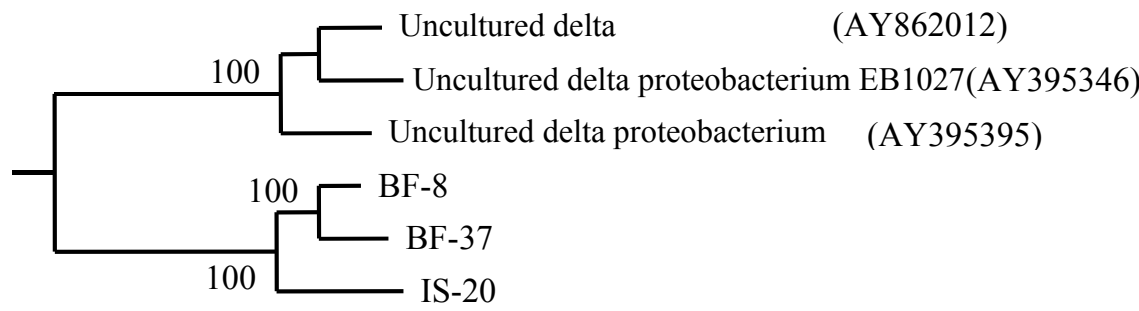

Figure 3: Phylogenetic analysis of bacterial clones related to $\delta$-Proteobacteria.

\subsection{Functional classification of diverse procaryotae}

Those clones isolated from biofilm and inner sludge were classified into aerobic bacteria (16 clones), anaerobic bacteria (30 clones), facultative anaerobic bacteria (23 clones), growth slowness bacteria ( 7 clones) and uncultured bacteria (4 clones) based on their sources of energy, carbon and terminal electron 
acceptor so as to detailed illustrate their contribution to decrement of excess sludge in GCOR [16].

0.05

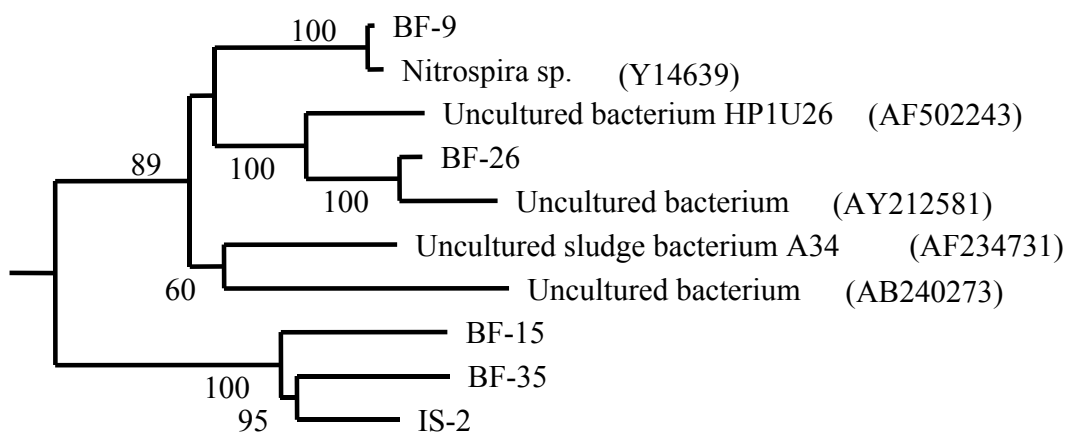

Figure 4: Phylogenetic analysis of bacterial clones related to unclassified bacteria.
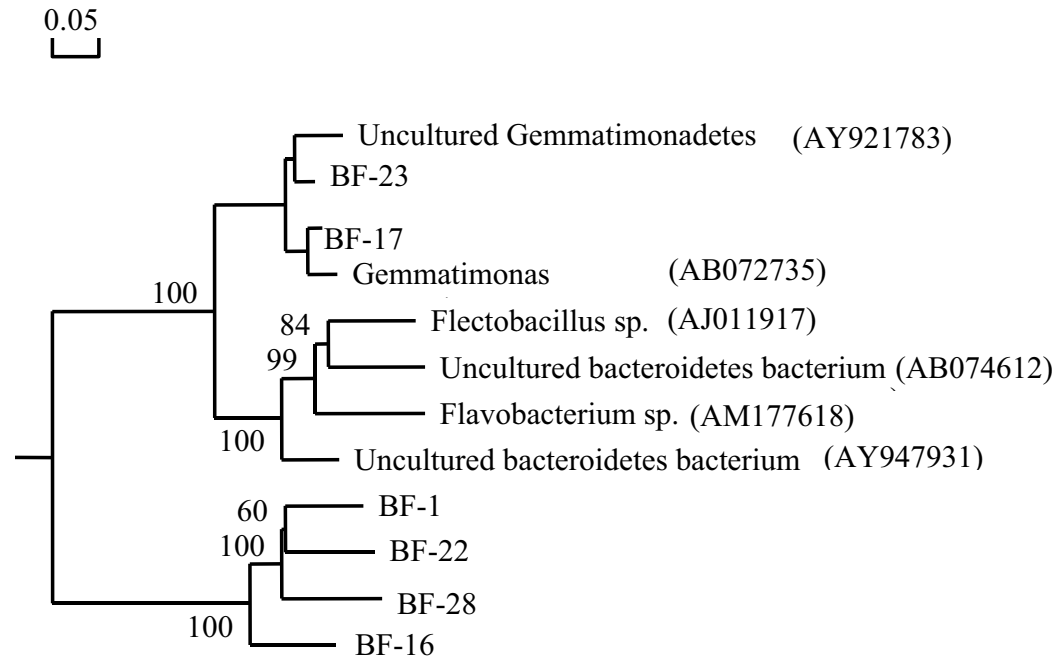

Figure 5: Phylogenetic analysis of bacterial clones related to bacteroidetes.

\section{Discussion}

\subsection{Ecological significance of dominant procaryotae in GCOR}

All of the sequences were isolated directly from the biofilm and inner sludge in GCOR. Even if we have to take care about the biases that affect PCR-based 16SrDNA analysis [16] and sampled from biofilm and inner sludge, we can nevertheless consider that the microorganisms detected represented the prokaryotic diversity in GCOR. 


\subsubsection{Biofilm}

The most dominant bacterial communities in biofilm with closed relationship were those species belonging to facultative anaerobic bacteria (37\% clones) and aerobic bacteria (26\% clones), based on their metabolic type. Anaerobic bacteria and growth slowness bacteria were especially found at the inner layer of biofilm.

Flectobacillus sp. was always detected in soil, fresh water and marine [15]. It is known to compete efficiently with one or several polyose for hydrochloric proionate and hydrochloric acetate. Aeromonas hydrophila classified into $\gamma^{-}$ proteobacteria was found to decompose carbonhydrate and glucose to produce combustion gas and $\mathrm{H}^{+}$, and hydrolyze solid organism like starch and glycerin to organic dissolved substance. A phylogenetically novel aerobic bacterium Gemmatimonas was isolated from an anaerobic-aerobic sequential batch reactor operated under enhanced biological phosphorus removal conditions for wastewater treatment [16]. Klebsiella planticola and Enterobacter phylogenetly related to the family Enterobacteriaceae had function to ferment glucose, carbonhydrate and ethyl alcohol into organic acid accompany with gas production.

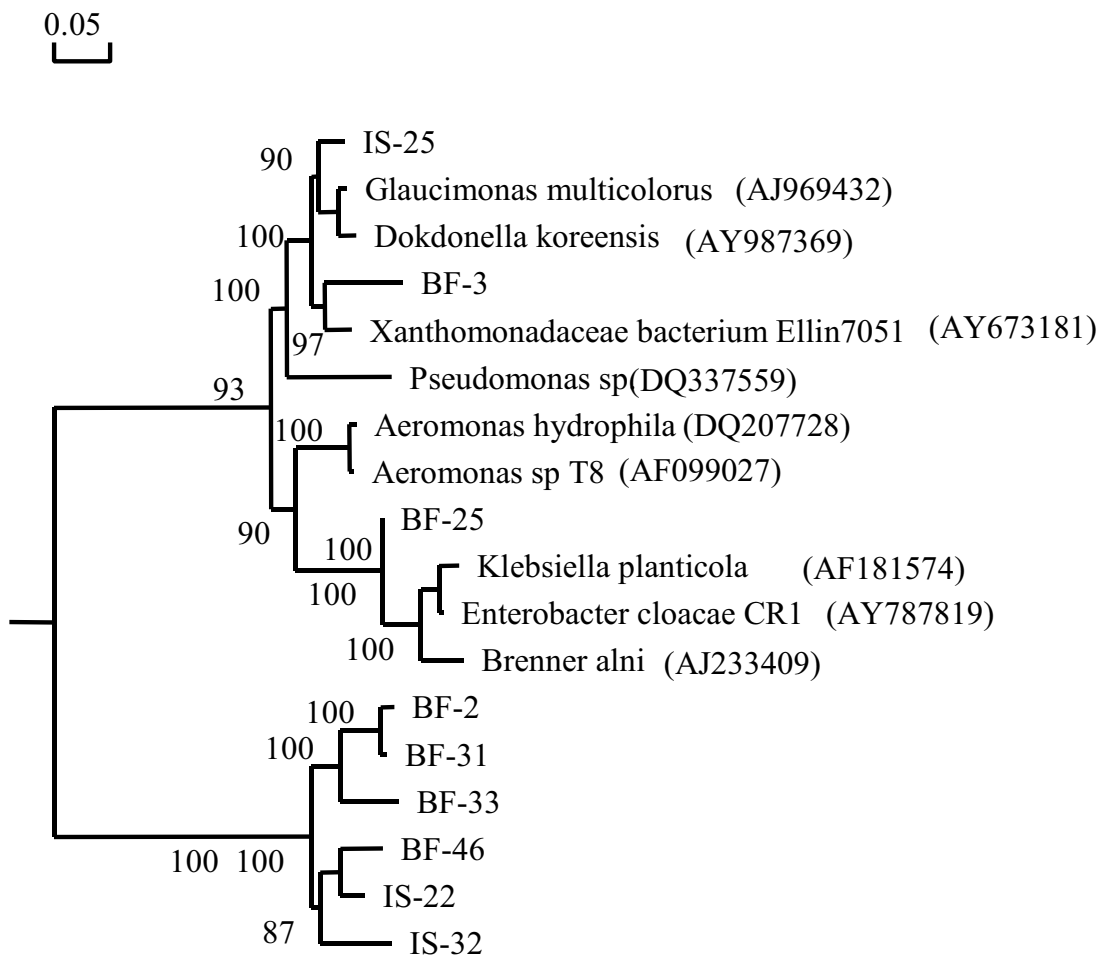

Figure 6: Phylogenetic analysis of bacterial clones related to $\gamma$-Proteobacteria. 


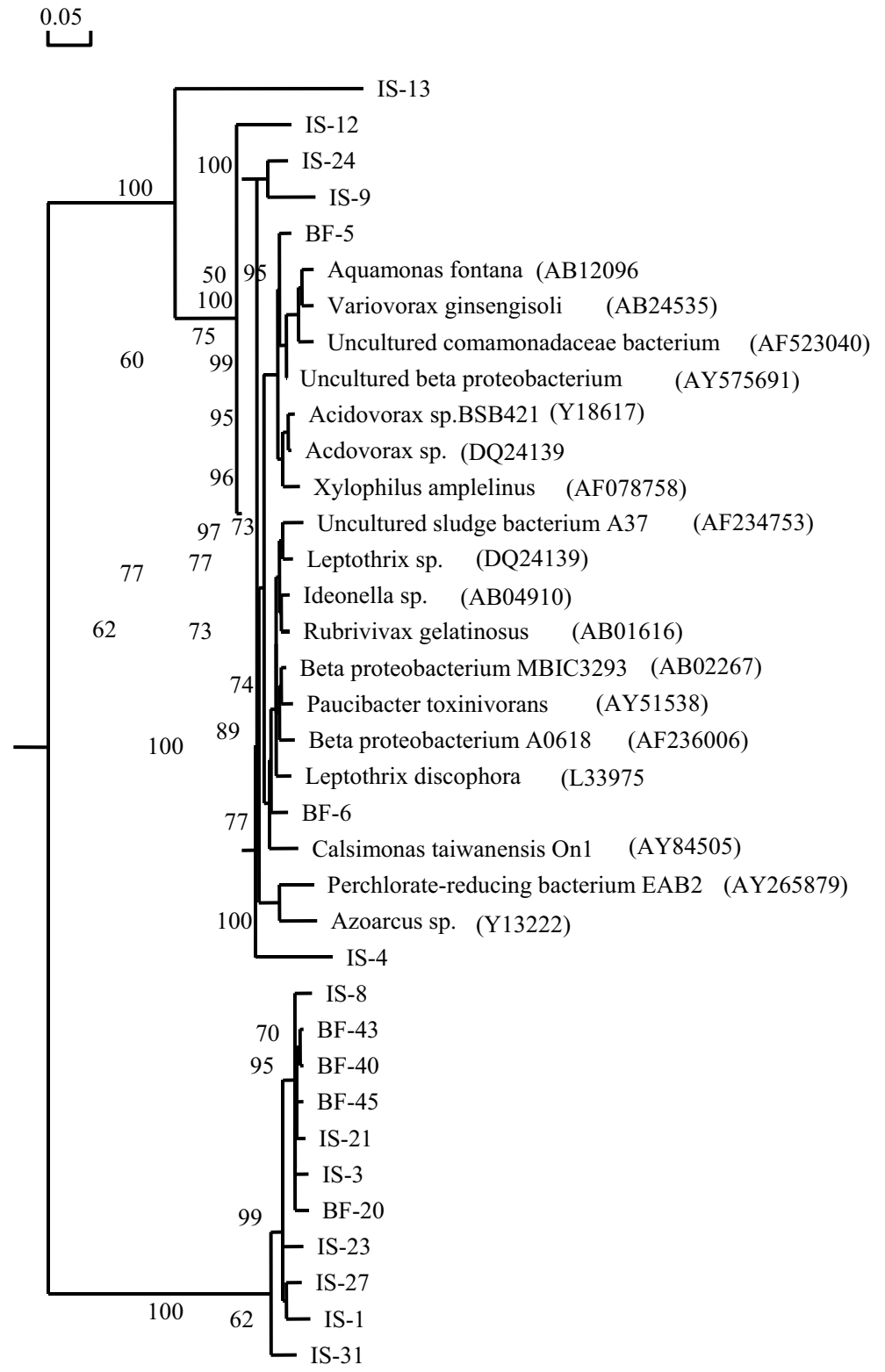

Figure 7: Phylogenetic analysis of bacterial clones related to $\beta$-Proteobacteria.

Xanthomonadaceae bacterium, Pseudomonas sp. and Acidovorax sp. classified to Pseudomonadaceae are able to degrade dissolved organism into ignorganism, $\mathrm{H}_{2} \mathrm{O}, \mathrm{CO}_{2}$ and energy for new bacteria growth. Meanwhile, 
Pseudomonas sp. was known as the host bacteria where parasitic bacteria like bacteriophage breeds and grows, and Acidovorax sp. was specially found to utilize 68 kinds of organism, for example, fructose as carbon nutrition for maintaining its growth. Aquamonas in respiratory metabolism could oxidize glucose, fructose and carbonhydrate, but it could also hydrolyze starch to organic dissolved substance. A novel bacteria Flavobacterium sp. was associated with amino acid through dissimilation of chemo-organotrophic acetate, especially in municipal sewage [19].

In addition, several species of anaerobic bacteria were detected at inner layer of biofilm within anaerobic condition suspectly. Leptothrix $s p$. was able to hydrolyze glucose to produce organic acid in sewage treatment. Even though bacteroidete bacterium was not classified into the same subdivision with Leptothrix sp., but it's metabolic type and function for decomposing solid organism to organic acid was similar to Leptothrix sp.

Comparing with aforementioned groups, two species of growth slowness bacteria were also detected in biofilm. Caldimonas taiwanensis grew well in minimal medium containing starch as the sole carbon source, and its extra cellular products expressed amylase activity, and Ideonella sp. initially isolated from wild rice [17] was most similar to Caldimonas taiwanensis in metabolism.

\subsubsection{Inner sludge}

In contrast to biofilm, anaerobic bacteria (36\% clones) and facultative anaerobic bacteria (30\% clones) were dominant group in inner sludge where was with less or no oxygen.

Comparing with anaerobic bacteria detected in biofilm, Perchlorate-reducing bacterium were especially found in inner sludge. It had the ability of indigenous microorganisms to degrade perchlorate more effectively at low concentrations of perchlorate [18], but also could photo-assimilated organic substrate into several kinds of organic acid. These results extend the current understanding of Perchlorate-reducing bacterium from diverse environments and provide added confidence that microbial perchlorate reduction is ubiquitous, even at highly contaminated sites, and can be harnessed effectively for bioremediation.

Table 3 showed that the species of facultative anaerobic bacteria detected from inner sludge were included in biofilm. The phylogenetic relationship of Erwinia alni 16S rRNA gene with family Enterobacteriaceae was also investigated by comparative $16 \mathrm{~S}$ rDNA analysis.

Four kinds of growth slowness bacteria isolated from inner sludge were different from biofilm. A novel bacteria named Paucibacter toxinivorans isolated initially from lake sediment had a capable of degrading cyanobacterial hepatotoxins microcystins and nodularin, and assimilated only a few carbon sources. It was able to mineralize phosphorus from organic compounds, and they had strong leucine arylamidase and chymotrypsin activities. Uncultured comamonadaceae bacterium, Xylophilus ampelinus and Variovorax ginsengisoli belonged to Burkholderiales subdivision were able to grow slowly in noncarbonated natural mineral waters. 
Dokdonella koreensis and Glaucimonas multicolorus appeared to be special members of aerobic group in inner sludge, but clarified into Xanthomonadaceae through phylogenetic relationship analysis of 16SrDNA sequences.

\subsection{Contributions of diverse procaryotae to excess sludge decrement in GCOR}

\subsubsection{Uncoupled metabolism}

We systematically evaluate the following possible scenarios that may explain the reduction of excess sludge in GCOR: (1) uncoupled metabolism, (2) diverse bacterial behaviour and (3) domination of slow growers.

Euan W. Low (1998) suggested that intercellular regulation of catabolic and anabolic processes by bacteria is necessary to ensure an efficient flow to energy. Bacteria anabolism is coupled to catabolism of substrate through rate limiting respiration. However, uncoupled metabolism would occur if respiratory control did not exist and instead the biosynthetic processes were rate limiting. Therefore excess free energy would be directed away from the production of biomass. The metabolite overproduction was occurred in many bacterial species under conditions of nutrient limitation and carbon substrate excess.

In GCOR this effect occurred for Klebsiella planticola isolated from biofilm and Pseudomonas sp. detected both from biofilm and inner sludge. For these bacterial growing, carbon substrate uptake and carbon dioxide evolution rates were greatly elevated under nutrient limited conditions, yet the biomass yield decreased almost $50 \%[1]$.

\subsubsection{Bacterial behaviour in GCOR}

GCOR contains diverse and interactive microbial population either in biofilm or in inner sludge. These heterogeneous microbial cells are undergoing life cycles and reproducing with relationships between the different types of cells being characterized by symbiotic, cooperative, aggressive and competitive behaviour, resulted in biomass reduction.

\subsubsection{Domination of slow growers}

Growth slowness bacteria were mostly found in GCOR. These bacteria utilized the autochthonous substrate formed from cell lysis productions as the only carbon source to maintain them growth, result in overall biomass reduction.

In conclusion, this study for the first time reports the detailed compositions of microbial communities associated with GCOR, a novel sewage treatment system. The evaluation of sample isolated and gene clone methods indicated that diverse microbial is one of main functions to excess sludge reduction in GCOR. Based on their 16SrRNA sequences, most of isolates belong to known bacterial species. Their contributions to excess sludge decrement were associated with uncoupled metabolism, diverse bacterial interactive behaviour and domination of slow growers. In order to in quantity illustrate bacterial function to excess sludge decrement, techniques FISH and DAPI are necessary. 


\section{References}

[1] Low E U, Chase H A, Milner M G, et al. Uncoupling of metabolism to reduce biomass production in the activated sludge process. Wat Res, 2000, 34 (12): 3204-3212.

[2] Guang-Hao Chen, Kyoung-Jin An, Sebastien Saby et al. Possible cause of excess sludge reduction in an oxic-settling-anaerobic activated sludge process. Wat Res, 2003, 37: 3855-3866.

[3] Esther M Gabor, Erik J de Vries, Dick B Janssen. Efficient recovery of environmental DNA for expression cloning by indirect extraction methods. FEMS Microbial Ecology, 2003, 44: 153-163.

[4] He Jizheng, Xu Zhihong Hughes Jane. Pre-lysis washing improves DNA extraction from a forest soil. Soil Biology \& Biochemistry, 2005 xx, 1-5.

[5] Lemarchand K, Berthiaume F, Maynard C et al. Optimization of microbial DNA extraction and purification from raw wastewater samples for downstream pathogen detection by microarrays. J Microbiological Methods, 2005, xx: xxx-xxx.

[6] Burgmann Helmut, Pesaro Manuel, Widmer Franco, et al. A strategy for optimizing quality and quantity of DNA extracted from soil. J Microbiological Methods, 2001, 45: 7-20.

[7] Linda L. Blackall, Paul C. Burrell, Heather Gwilliam et al. The use of 16SrDNA clone libraries to describe the microbial diversity of activated sludge communities. Wat Sci Tech. 1998, 37: 451-454.

[8] Hemant J. Purohit, Atya Kapley, Aditi A, et al. A novel approach for extraction of PCR-compatible DNA from activated sludge samples collected from different biological effluent treatment plants. J Microbiological Methods, 2003, 52: 315-323.

[9] Ruben Araya, Katsuji Tani, Tasuya Takagi, et al. Bacterial activity and community composition in stream water and biofilm from an urban river determined by fluorescent in situ hybridization and DGGE analysis. FEMS Microbiology Ecology, 2003, 43: 111-119.

[10] G. Silyn-Roberts, G. Lewis. In situ analysis of nitrosomonas spp. in wastewater treatment wetland biofilms. Wat Res 2001, 35: 2731-2739.

[11] Estelle Masseret, Christain Amblard, Gilles Bourdier. Changes in the structure and metabolic activities of periphytic communities in a stream receiving treated sewage from a waste stabilization pond. Wat Res 1998, 32: 2299-2314.

[12] Sophie Mouné, Pierre Caumette, Robert Matheron et al. Molecular sequence analysis of prokaryotic diversity in the anoxic sediments underlying cyanobacterial mats of two hypersaline ponds in Mediterranean salterns. FEMS Microbiology Ecology, 2003, 44: 117-130.

[13] Agnès Grabowski, Olivier Nercessian, Francoise Fayolle et al. Microbial diversity in production waters of a low-temperature biodegraded oil reservoir. FEMS Microbiology Ecology, 2005, 54: 427-443. 
[14] Cunha, S., Tiago, I., Luisa Pires, A., da Costa, M.S. and Verissimo, A. Dokdonella fugitiva sp. nov., a Gammaproteobacterium isolated from potting soil, JOURNAL Syst. Appl. Microbiol. 2006, 29 (3), 191-196.

[15] Chen WM, Chang JS, Chang SC et al. Caldimonas taiwanensis sp. nov., a amylase producing bacterium isolated from a hot spring. Syst Appl Microbiol. 2005, 28(5):415-420.

[16] Waller, A.S., Cox, E.E. and Edwards, E.A. Perchlorate-reducing microorganisms isolated from contaminated sites. Environ. Microbiol. 2004, 6 (5), 517-527.

[17] Sproer, C., Mendrock, U., Swiderski, J., Lang, E. and Stackebrandt, E. The phylogenetic position of Serratia, Buttiauxella and some other genera of the family Enterobacteriaceae. Int. J. Syst. Bacteriol. 1999, 49 Pt 4, 1433-1438.

[18] Rapala, J., Berg, K.A., Lyra, C. et al. Paucibacter toxinivorans gen. nov., sp. nov., a bacterium that degrades cyclic cyanobacterial hepatotoxins microcystins and nodularin. Int. J. Syst. Evol. Microbiol. 2005, 55 (PT 4), 1563-1568.

[19] Bourrain, M., Achouak, W., Urbain, V., et al. 1999. DNA extraction from activated sludges. Curr. Microbiol. 38, 315-319.

[20] Horan N. J. 1990. Biological Wastewater Treatment System. Wiley, Chichester.

[21] Low, E. W. and Chase H. A. 1999. Redecing Production of Excess Biomass during Wastewater Treatment. Wat. Res. Vol. 33, No.5: 1119-1132 